\title{
A Study on Adiabatic Temperature Rise Test and Temperature Stress Simulation of Rock-Fill Concrete
}

\author{
Xiaofei Zhang $\mathbb{B D}^{1}{ }^{1}$ Qian Liu, ${ }^{1}$ Xin Zhang, ${ }^{1}$ Yanlong Li $\mathbb{D},{ }^{1}$ and Xiaoping Wang ${ }^{2}$ \\ ${ }^{1}$ State Key Laboratory Base of Eco-Hydraulic Engineering in Arid Area, Xian University of Technology, Xian 710048, China \\ ${ }^{2}$ China Hydropower Consulting Group, Northwest Institute of Survey and Design, Xian 710075, China
}

Correspondence should be addressed to Xiaofei Zhang; zhangxiaofei_lgd@163.com

Received 28 June 2018; Revised 3 September 2018; Accepted 20 September 2018; Published 21 October 2018

Academic Editor: Farhad Aslani

Copyright (c) 2018 Xiaofei Zhang et al. This is an open access article distributed under the Creative Commons Attribution License, which permits unrestricted use, distribution, and reproduction in any medium, provided the original work is properly cited.

In the present study, we investigate the effect of the adiabatic temperature rise property of rock-fill concrete (RFC) on the temperature stress and crack resistance of RFC gravity dams. We conducted tests on the adiabatic temperature rise of RFC with a rock-fill ratio of $42 \%, 49 \%$, and $55 \%$, respectively. Based on the regression analysis of the test data, a calculation model of the adiabatic temperature rise, considering the rock-fill ratio, is developed, and the finite element analysis software ANSYS is employed to simulate the whole process of the temperature and temperature stress fields of a RFC gravity dam. The main findings of the study are as follows: (1) Both the adiabatic temperature rise rate and the final adiabatic temperature rise of RFC are negatively correlated with the rock-fill ratio. (2) The calculation model of the adiabatic temperature rise of RFC is characterized by its high accuracy, which can help predict the adiabatic temperature rise of RFC with different rock-fill ratios. (3) Without any temperature control measures, the maximum temperature stress of RFC generated by the temperature rise of hydration heat in the RFC gravity dam is $0.93 \mathrm{MPa}$, which meets the standard of temperature stress control. The results of the present study indicate that dam construction with RFC can simplify the measures of temperature control and crack prevention, improve the construction efficiency, and reduce the cost of dam construction.

\section{Introduction}

Rock-fill concrete (RFC) is a new type of concrete developed from self-compacting concrete (SCC) and makes full use of its advantages, such as high fluidity, segregation resistance, and filling-ability. It also breaks through the limitations of traditional construction technology, in which SCC filling rock-filled voids solely depends on self-gravity, not by forced vibration to form a mass concrete with integrity, high density, and enhanced strength [1-4]. In comparison with conventional mass concrete, RFC possesses the following engineering and economic advantages [5-7]: (1) The high fluidity and cohesive force of SCC ensures the high density and strength of RFC. (2) As the main building material, a large number of block stones guarantee low cement consumption with RFC, decreasing construction costs and simplifying temperature control. (3) The exclusion of vibration from construction technology can simplify or eliminate surface treatment measures, shorten construction time, and significantly improve construction efficiency. (4) The substitution of RFC with waste concretes and tailings can realize the resource utilization of solid waste and extensively reduce construction energy consumption and emission. RFC was first proposed and applied for national patent by Prof. Jin Feng and Prof. An Xuehui from Tsinghua University in 2003 [8]. In 2012, RFC successfully entered the List of Circular Economy Technology, Technology and Equipment encouraged by China National Development and Reform Commission and received a wide application in the field of water conservancy and hydropower engineering thereafter [9]. RFC has created remarkable economic, social, and environmental benefits with its obvious technical advantages and has been utilized in the construction of Baoquan pumped storage power station in Henan Province, Changkeng thirdlevel reservoir reconstruction in Zhongshan of Guangdong Province, the back-filling of the caisson group Xiang Jiaba 
hydropower station of the Jinsha River in Sichuan Province, and the hydro-junction cofferdam at the mountain pass of Buerjin.

With the wider application of RFC within the domain of water conservancy and hydropower engineering, a greater importance has been attached to the effect of heat released by cement hydration on the endurance and stability of an RFC structure [10]. During RFC's hardening process, the heat produced by cement hydration leads to an increase in concrete temperature. Moreover, concrete's poor temperature conductivity promotes slow heat dissipation to the outside, generating large tensile stress during the periods of temperature drop, which ultimately leads to temperature cracks in the RFC structure, influencing the durability and security of the concrete structure $[11,12]$. An adiabatic temperature rise serves as an important thermal indicator affecting the temperature stress and crack resistance of the concrete structure. Hence, it is imperative to study the adiabatic temperature rise property in order to quantify the temperature stress of RFC and evaluate the effect of temperature cracks on RFC. In recent years, a large number of researchers have conducted theoretical and numerical simulation studies on the property of adiabatic temperature rise. Zhu Bofang [13] derived the adiabatic temperature rise expression for concrete, considering the influence of temperature, and discussed the inversion method of the adiabatic temperature rise of concrete according to the measured engineering temperature. Lim C. K. et al. [14] developed a new method that can be easily applied to mass concrete structures and has a high accuracy in predicting the characteristics of adiabatic temperature rise of concrete. Yao Wu et al. [15-17] proposed the increment formula of the adiabatic temperature rise of concrete based on the dynamic hydration equation of cement. $\mathrm{Ng}$ I. Y. T. et al. $[18,19]$ launched an experimental program to investigate the coupled effects of cement and water contents on the adiabatic temperature rise of concrete. Wang Licheng et al. [20] developed a mesoscale lattice network model to analyze the heat transport process in concrete and also conducted a timevarying numerical simulation of the temperature distribution and fields affected by the boundary conditions for early-age concrete. Mai Ge et al. [21] reported the equivalent calculation model in order to obtain the mathematical equation of the temperature field of RFC and successfully generated the analytical solution of the temperature field distribution. Evsukoff A. et al. [22] presented a data mining approach for modeling the adiabatic temperature rise during concrete hydration.

However, the above-mentioned studies only dealt with the mesoscopic simulation of the adiabatic temperature rise performance of concrete from both theoretical and numerical simulations. Owing to the imperfect aggregate generation algorithm and complex grid partitioning algorithm, the mesoscopic simulation of the adiabatic temperature rise of concrete in an actual application has yet to be adequately expounded.

As a new type of mass concrete, RFC is developing rapidly. Due to the existence of a large amount of rock-fill, the thermal properties of RFC such as hydration temperature rise must vary from that of conventional mass concrete.
The temperature stress characteristics of using RFC to build dams are currently unclear, and important questions still remain: whether temperature control measures are needed and what measures should be taken. Therefore, in this paper, RFC is regarded as a homogeneous and isotropic material, and the experimental study on the adiabatic temperature rise of the SCC and the scaling small-diameter RFC in proportion with rock-fill ratio of $42 \%, 49 \%$, and $55 \%$ is conducted, while attempting to investigate the effect of rockfill ratio on the adiabatic temperature rise of RFC. This is followed by the regression analysis of the test data in order to derive the calculation model of the adiabatic temperature rise of RFC, while considering the rock-fill ratio. Furthermore, taking a RFC gravity dam with a rock-fill ratio of $55 \%$ as an example, a simulation of the whole-process temperature and temperature stress fields of the overflow dam during construction and operation is conducted in order to gain the distribution rules of temperature and temperature stress, which is using the finite element analysis software ANSYS and in accordance with material characteristics of the RFC and specific construction progress of the dam. The results provide greater insight and reference for the design and construction of similar practical projects.

\section{The Adiabatic Temperature Rise Test of Rock-Ill Concrete}

2.1. Test Instrument and Principle. The hydration heat of cement is an important factor affecting the temperature stress of concrete, and the thermal parameter used in the actual temperature field calculation is the adiabatic temperature rise of concrete. There are two methods for measuring the adiabatic temperature rise of concrete [11].

(1) Direct method: the adiabatic temperature rise of concrete is directly measured by the test equipment. (2) Indirect method: hydration heat of cement is measured first; then the adiabatic temperature rise according to the hydration heat and specific heat, bulk weight, and cement content of the concrete are calculated. However, it is known that there are considerable differences between the concrete adiabatic temperature rise obtained by the indirect method and the value directly measured through the concrete adiabatic temperature rise test. Therefore, if possible, the adiabatic temperature rise test of concrete should be carried out.

In this test, the adiabatic temperature rise of RFC is directly measured by NELD-TV810 concrete adiabatic temperature rise test chamber. The design principle is shown in Figure 1. The main technical indicators are as follows.

(1) The precision of temperature tracing between the center of the specimen and the test chamber should be less than $0.1^{\circ} \mathrm{C}$.

(2) The temperature drift of $50 \mathrm{~L}$ water for $72 \mathrm{~h}$ should be less than $0.5^{\circ} \mathrm{C}$.

It is necessary to ensure that the temperature of concrete can neither radiate to the external environment nor reverseheat the specimen when the temperature of the external environment is higher than the concrete's during the test. Thus, an adiabatic closed space is provided to the concrete specimen to ensure the adiabatic temperature rise of the whole test 


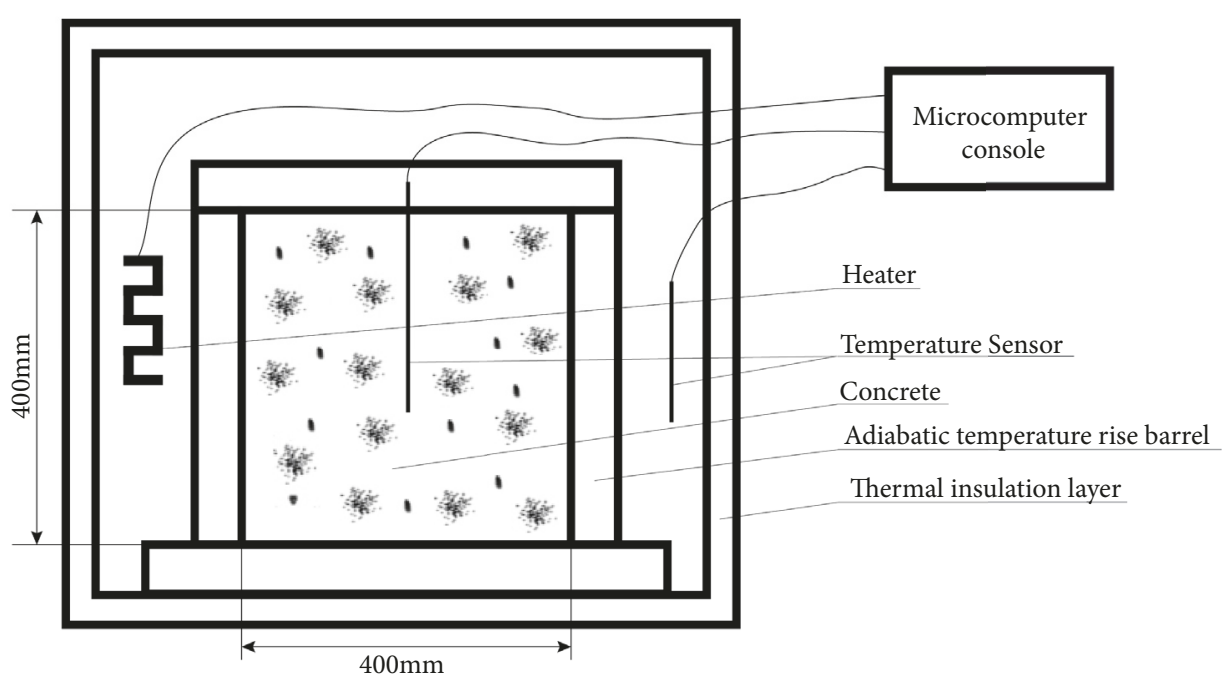

FIGURE 1: Schematic diagram of NELD-TV810 concrete adiabatic temperature rise tester.

process. The double-layered temperature controlled device can effectively solve the effect on the whole system and the hysteresis on the tracking heating device caused by constantly changing external temperature. In general, the specification requires a constant temperature for the test equipment; an outer heating temperature control installation can effectively shield the interference of the external environment, which results in a higher accuracy of the test results.

\subsection{The Adiabatic Temperature Rise Test of SCC. RFC consists} of SCC and rock-fill, and its temperature rise of hydration heat originates from the SCC. As a result, an investigation into the adiabatic temperature rise characteristics of SCC is required to study the adiabatic temperature rise of RFC. In the present study, the SCC, with design strength of C20, is employed, with the mix proportion shown in Table 1, which is referred to as the actual mix proportion of RFC gravity dam that follows. The slump of the SCC should be determined prior to putting it in the measuring instrument for the adiabatic temperature rise, in order to ensure design fluidity. The temperature should be measured every $10 \mathrm{~min}$, and the precision of temperature tracking between the center of the SCC specimen and the adiabatic temperature rise test chamber should be less than $0.1^{\circ} \mathrm{C}$.

According to the mix proportions shown in Table 1, self-compacting concrete is mixed and tested in accordance with SL352-2006 Test Regulations for Hydraulic Concrete. The adiabatic temperature rise of SCC reaches ca. $95 \%$ of the final adiabatic temperature rise on the 5th day of testing. After the 10th day of testing, the center temperature of the SCC specimen remains constant, and the interior maximum temperature rise of the specimen is $26.20^{\circ} \mathrm{C}$. Figure 2 shows the adiabatic temperature rise curve of the SCC. It is known that the relationship between the adiabatic temperature rise $\theta(\tau)$ and concrete age $\tau$ represented by the composite exponents is more consistent with the experimental data [11].
Therefore, the relationship between adiabatic temperature rise and age of SCC is expressed as follows:

$$
\theta_{0}(\tau)=26.25\left(1-e^{-0.769 \tau^{0.812}}\right)
$$

where $\theta_{0}(\tau)$ refers to the accumulative adiabatic temperature rise of SCC (its unit is ${ }^{\circ} \mathrm{C}$ ) and $\tau$ is the age of SCC (its unit is day).

\subsection{The Adiabatic Temperature Rise Test of Small-Diameter} RFC with Different Rock-Fill Ratios. In the engineering field, RFC with varying rock-fill ratios is generally prepared according to actual demands. The adiabatic temperature rise characteristics of RFC with different rock-fill ratios differ due to the various amounts of SCC. In order to investigate the effect of rock-fill ratio on the adiabatic temperature rise of $\mathrm{RFC}$, it is necessary to carry out a test with varying rock-fill ratios, which is expressed in volumetric ratios.

Currently in practical engineering, the size of the rockfill particles is generally within the range of 30 to $1000 \mathrm{~mm}$. In this test, the NELD-TV810 type concrete adiabatic temperature rise test chamber is employed with a size of $400 \mathrm{~mm}$ (diameter) $\times 400 \mathrm{~mm}$ (barrel height). According to SL3522006 Test Regulations for Hydraulic Concrete, the container size of the measuring instrument for the adiabatic temperature rise should be not less than three times the maximum aggregate diameter. Due to container size limitations, the original size test cannot be conducted directly. Previous studies [6] have shown that the particle size of RFC exerts no direct effect on the adiabatic temperature rise. On this basis, the adiabatic temperature rise test of small-diameter RFC can be conducted by scaling the actual rock-fill diameter in proportion according to the barrel size. The particle size after scaling should be between 40 and $130 \mathrm{~mm}$. From a macroscopic point of view, the adiabatic temperature rise is a thermal parameter caused by the thermal behavior 
TABLE 1: The mix proportion of C20 self-compacting concrete.

\begin{tabular}{lcccccc}
\hline Material & Cement & Flyash & Sand & Stone & Water & Admixture \\
\hline Usage $\left(\mathrm{kg} / \mathrm{m}^{3}\right)$ & 219.00 & 204.00 & 1255.00 & 545.00 & 205.00 & 6.70 \\
\hline
\end{tabular}

TABLE 2: The mix proportion of rock-fill concrete with different rock-fill ratios.

\begin{tabular}{lccccccrr}
\hline Material & & Cement & Flyash & Sand & Stone & Water & Admixture & Rock-fill \\
\hline & $42 \%$ & 133.61 & 124.46 & 765.66 & 332.50 & 125.07 & 4.09 & 1075.62 \\
Usage $\left(\mathrm{kg} / \mathrm{m}^{3}\right)$ & $49 \%$ & 120.52 & 112.27 & 690.68 & 299.94 & 112.82 & 3.69 & 1294.08 \\
& $55 \%$ & 110.14 & 102.59 & 631.16 & 274.09 & 103.10 & 3.37 & 1496.55 \\
\hline
\end{tabular}

TABLE 3: The adiabatic temperature rise of SCC and RFC at different ages.

\begin{tabular}{lccccccccccc}
\hline Concrete age (day) & 1 & 3 & 5 & 7 & 9 & 11 & 13 & 15 & 21 & 28 & 44 \\
\hline SCC $\left({ }^{\circ} \mathrm{C}\right)$ & 14.08 & 22.23 & 24.72 & 25.62 & 25.98 & 26.13 & 26.20 & 26.22 & 26.25 & 26.25 & 26.25 \\
\hline RFC with a rock-fill ratio of $42 \%\left({ }^{\circ} \mathrm{C}\right)$ & 8.46 & 15.23 & 17.60 & 18.50 & 18.86 & 19.01 & 19.07 & 19.09 & 19.11 & 19.11 & 19.11 \\
\hline RFC with a rock-fill ratio of $49 \%\left({ }^{\circ} \mathrm{C}\right)$ & 6.18 & 11.97 & 14.61 & 15.90 & 16.56 & 16.91 & 17.10 & 17.20 & 17.30 & 17.32 & 17.32 \\
\hline RFC with a rock-fill ratio of $55 \%\left({ }^{\circ} \mathrm{C}\right)$ & 4.22 & 8.62 & 11.08 & 12.58 & 13.53 & 14.15 & 14.56 & 14.84 & 15.24 & 15.39 & 15.45 \\
\hline
\end{tabular}

of concrete hydration. As long as the characteristics and proportion of the concrete's materials remain unchanged, the adiabatic temperature rise will not be affected. Therefore, the adiabatic temperature rise test of a small-diameter RFC can completely replace the original size of RFC adiabatic temperature rise test.

In hydraulic engineering, the rock-fill ratio of RFC is generally between 40 and $60 \%$. Therefore, in this paper, three groups of small-diameter RFC were selected for the adiabatic temperature rise test using typical rock-fill ratios of $42 \%, 49 \%$, and 55\%. The mix proportions are shown in Table 2.

Using the mix proportions shown in Table 2, three groups of RFC were mixed and tested in accordance with SL352-2006 Test Regulations for Hydraulic Concrete. On the 7 th day of the test, the adiabatic temperature rise of RFC with $42 \%$ rock-fill ratio reaches ca. $95 \%$ of the final adiabatic temperature rise, and after the 13th day of the test, the central temperature of the RFC specimen remains constant, with the interior maximum temperature rise of the specimen being $19.11^{\circ} \mathrm{C}$; the adiabatic temperature rise of the RFC with $49 \%$ rock-fill ratio reaches ca. $95 \%$ of the final adiabatic temperature rise on the 9th day of the test, with the central temperature of the RFC specimen remaining constant on the 15 th day; the interior maximum temperature rise of the specimen is $17.23^{\circ} \mathrm{C}$; the adiabatic temperature rise of the RFC with 55\% rock-fill ratio reaches ca. $95 \%$ of the final adiabatic temperature rise on the 15 th day of the test, and the central temperature of the RFC specimen does not increase after the 21st day; the interior maximum temperature rise of the specimen is $15.29^{\circ} \mathrm{C}$.

According to the measured adiabatic temperature rise of RFC, the function curves of adiabatic temperature rise of RFC depending on the age of RFC with the rock-fill ratio of $42 \%, 49 \%$, and $55 \%$ are shown in Figure 3, and the composite exponential fitting formulas are as shown in formulas (2), (3), and (4), respectively.

$$
\begin{aligned}
& \theta_{1}(\tau)=19.11\left(1-e^{-0.585 \tau^{0.912}}\right) \\
& \theta_{2}(\tau)=17.32\left(1-e^{-0.441 \tau^{0.892}}\right) \\
& \theta_{3}(\tau)=15.45\left(1-e^{-0.319 \tau^{0.855}}\right)
\end{aligned}
$$

where $\theta_{i}(\tau)(i=1,2,3)$ corresponds to the accumulative adiabatic temperature rise of RFC with a rock-fill ratio of $42 \%$, $49 \%$, and $55 \%$ with the age of $\tau$ (the unit is ${ }^{\circ} \mathrm{C}$ ) and $\tau$ is the age of RFC (the unit is day).

\subsection{The Effect of Rock-Fill Ratio on Adiabatic Temperature} Rise of RFC. The results of the adiabatic temperature rise test show that the final adiabatic temperature rise for RFC decreases with increasing rock-fill ratio. That is, the final adiabatic temperature rise of RFC is negatively correlated with its rock-fill ratio. Based on the adiabatic temperature rise test results, a linear relationship between the final adiabatic temperature rise of RFC and the rock-fill ratio with the range of $40-60 \%$ is observed (Figure 4 ).

$$
\theta_{0}=-28.083 \eta+30.96
$$

where $\theta_{0}$ refers to the final adiabatic temperature rise of RCC (its unit is ${ }^{\circ} \mathrm{C}$ ) and $\eta$ is the rock-fill ratio of RFC.

Based on the composite exponential fitting results of the adiabatic temperature rise of SCC and RFC, a list with a rockfill ratio of $42 \%, 49 \%$, and $55 \%$ at different ages was generated (Table 3). According to the data, the adiabatic temperature rise rate of RFC decreases with an increase in rock-fill ratio. Moreover, the adiabatic temperature rise rate of SCC and RFC decreases with an increase in concrete age.

We found that the higher the ratio of rock-fill, the lower the final adiabatic temperature rise and rate of RFC. The reason is that all the hydration heat of RFC originates from 


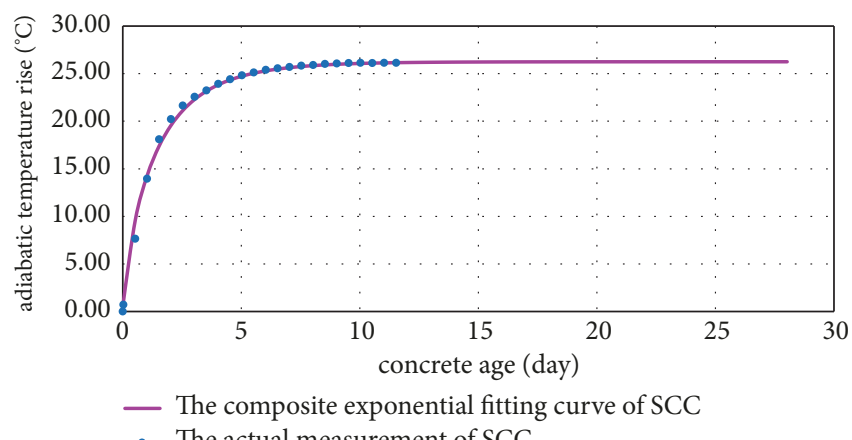

FIgURE 2: The adiabatic temperature rise curve of self-compacting concrete.

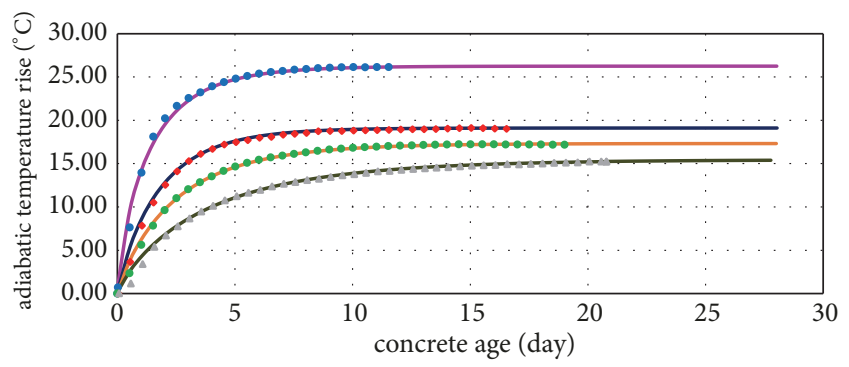

- The composite exponential fitting curve of SCC

- The composite exponential fitting curve of RFC (42\%)

- The composite exponential fitting curve of RFC (49\%)

- The composite exponential fitting curve of RFC (55\%)

- The actual measurement of SCC

- The actual measurement of RFC (42\%)

- The actual measurement of RFC (49\%)

$\triangle$ The actual measurement of RFC (55\%)

FIgURE 3: The adiabatic temperature rise curves of rock-fill concrete with different rock-fill ratios.

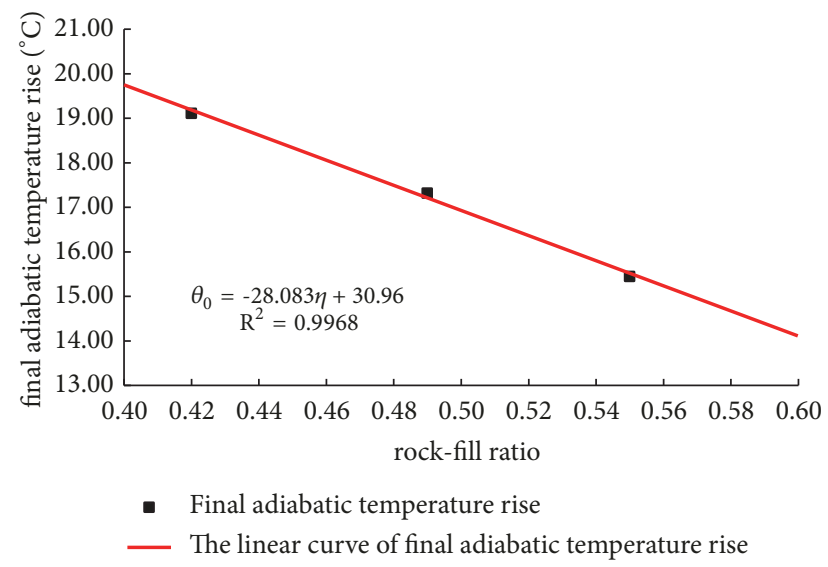

FIGURE 4: The relationship curve between the rock-fill ratio and the final adiabatic temperature rise.

cement, the rock itself does not generate heat, and part of the heat generated by the cement hydration reaction should gradually heat the rock-fill. Therefore, the adiabatic temperature rise of SCC far exceeds that of RFC, and the RFC is conducive to reduce the actual hydration heat temperature rise of mass concrete structures.

\section{The Calculation Model for Adiabatic Temperature Rise of RFC}

There are many factors affecting adiabatic temperature rise of RFC. For general RFC, when analyzing the conventional temperature problem, the nonuniformity effect of rock-fill on temperature and temperature stress field can be neglected. Microscopically, the adiabatic temperature rise of RFC can be obtained through the thermal parameters of rock-fill and SCC by weighted average according to each part [5]. Assuming that the rock-fill in RFC does not generate heat, the calculation model for the adiabatic temperature rise of RFC with a rock-fill ratio between 40 and $60 \%$ can be derived in accordance with the heat balance equation. Supposing the final adiabatic temperature rise of SCC is $\theta_{s c c}$, then the final adiabatic temperature rise of the RFC is as follows:

$$
\begin{aligned}
\theta_{R F C} & =\frac{m_{s c c} c_{s c c}}{m_{s c c} c_{s c c}+m_{\text {rock }} c_{\text {rock }}} \theta_{s c c} \\
m_{s c c} & =\rho_{s c c} V_{s c c} \\
m_{\text {rock }} & =\rho_{\text {rock }} V_{\text {rock }}
\end{aligned}
$$

where $m_{\text {rock }}$ and $m_{s c c}$ represent the mass of the rock-fill and SCC, respectively (the unit is $\mathrm{kg}$ ); $c_{\text {rock }}$ and $c_{s c c}$ represent the specific heat of the rock-fill and SCC, respectively (the unit is $\left.\mathrm{k} \bullet\left(\mathrm{kg} \bullet{ }^{\circ} \mathrm{C}\right)^{-1}\right) ; \rho_{\text {rock }}$ and $\rho_{s c c}$ represent the density of the rock-fill and SCC, respectively (the unit is $\mathrm{kg} / \mathrm{m}^{3}$ ); and $V_{\text {rock }}$ and $V_{s c c}$ represent the usage of the rock-fill and SCC per unit volume, respectively (the unit is $\mathrm{m}^{3}$ ).

Incorporating formula (7) into formula (6) is as follows

$$
\begin{aligned}
\theta_{R F C} & =\frac{V_{s c c}}{V_{s c c}+\rho_{\text {rock }} c_{\text {rock }} / \rho_{s c c} c_{s c c}} \theta_{s c c} \\
\frac{\rho_{\text {rock }} c_{\text {rock }}}{\rho_{s c c} c_{s c c}} & =\frac{V_{s c c}\left(\theta_{s c c}-\theta_{R F C}\right)}{\theta_{R F C} V_{\text {rock }}}
\end{aligned}
$$

According to the composite exponential fitting results of the adiabatic temperature rise of SCC and RFC, substituted with the three sets of data, which are in the first three columns 
TABLE 4: Comparison between the test and calculation values of adiabatic temperature rise.

\begin{tabular}{|c|c|c|c|c|c|c|}
\hline $\begin{array}{l}\text { Rock-fill ratio } \\
(\%)\end{array}$ & $\begin{array}{l}\text { The usage of } \\
\text { SCC per unit } \\
\text { volume } \\
\left(\mathrm{m}^{3}\right)\end{array}$ & $\begin{array}{l}\text { The test value } \\
\left({ }^{\circ} \mathrm{C}\right)\end{array}$ & $\begin{array}{c}\text { Interim } \\
\text { parameter } \\
\frac{\rho_{\text {rock }} c_{\text {rock }}}{\rho_{\text {scc }} c_{s c c}}\end{array}$ & $\begin{array}{c}\text { Arithmetic } \\
\text { mean } \\
\frac{\rho_{\text {rock }} c_{\text {rock }}}{\rho_{s c c} c_{s c c}}\end{array}$ & $\begin{array}{c}\text { The theoretical } \\
\text { calculation } \\
\text { value } \\
\left({ }^{\circ} \mathrm{C}\right)\end{array}$ & $\begin{array}{c}\text { Deviation } \\
\left({ }^{\circ} \mathrm{C}\right)\end{array}$ \\
\hline 42 & 0.58 & 19.11 & 0.5160 & \multirow{3}{*}{0.5415} & 18.86 & 0.25 \\
\hline 49 & 0.51 & 17.32 & 0.5366 & & 17.27 & 0.05 \\
\hline 55 & 0.45 & 15.45 & 0.5719 & & 15.80 & 0.35 \\
\hline
\end{tabular}

TABLE 5: The monthly mean temperature at the dam site.

\begin{tabular}{lcccccccccccc}
\hline Month & 1 & 2 & 3 & 4 & 5 & 6 & 7 & 8 & 9 & 10 & 11 & 12 \\
\hline Temperature $\left({ }^{\circ} \mathrm{C}\right)$ & -12.5 & -11.3 & -5.2 & 2.8 & 10.5 & 15.5 & 18.5 & 17.4 & 12.5 & 5.9 & -2.3 & -9.7 \\
\hline
\end{tabular}

of Table 4, into formula (9) and by calculating the arithmetic average, we obtain

$$
\frac{\rho_{\text {rock }} c_{\text {rock }}}{\rho_{s c c} c_{s c c}}=0.5415
$$

In conclusion, the adiabatic temperature rise of the RFC with a rock-fill ratio between 40 and $60 \%$ is expressed as follows:

$$
\theta_{R F C}=\frac{V_{s c c}}{V_{s c c}+0.5415} \theta_{s c c}
$$

Regression analysis was carried out to determine the relevant interim parameters in accordance with the composite exponential fitting results of the adiabatic temperature rise of SCC and RFC, which is in the fourth column of Table 4. The calculation model is then derived for the adiabatic temperature rise of RFC to allow for further comparison between the test and theoretical calculation values, as shown in Table 4. The results indicate that the deviation between the test and calculated value is less than $0.5^{\circ} \mathrm{C}$, and therefore the calculation model for the adiabatic temperature rise of RFC, with the rock-fill ratio taken into consideration, is characterized with high accuracy and strong applicability. Therefore, this can provide a theoretical basis for the prediction of the adiabatic temperature rise of RFC with different rock-fill ratios.

\section{Engineering Example Analysis}

4.1. Engineering Situation. In a hydro-junction project, the RFC gravity dam serves as a water retaining structure, with a rock-fill ratio of $55 \%$. The maximum dam height is $49 \mathrm{~m}$, and the crest length is $122.43 \mathrm{~m}$. Facing the main riverbed, there is an overflow dam with no gate control, which is $46 \mathrm{~m}$ in height.

\subsection{Calculation Parameters}

4.2.1. Meteorological Data. Table 5 shows the statistical data of the monthly mean temperature at the dam site.
After the reservoir storage, water temperature can be calculated according to the following formula [11]:

$$
\begin{aligned}
T(z) & =c+\left(T_{s}-c\right) e^{-0.04 z} \\
c & =\frac{\left(T_{b}-T_{s} e^{-0.04 H}\right)}{\left(1-e^{-0.04 H}\right)}
\end{aligned}
$$

where $T(z)$ refers to the water temperature at a depth of $z ; T_{b}$ and $T_{s}$ refer to the monthly mean water temperature at the bottom and surface of the reservoir, as is shown in Table 6 ; and $H$ refers to the reservoir depth, the height difference between the surface of the reservoir and the top of the constant temperature water body.

4.2.2. Construction Schedule. On May 8th, 2014, the pouring of normal concrete cushion with $1 \mathrm{~m}$ thickness began. Then the consolidation grouting of the dam's foundation was performed from May 9th, 2014, to June 7th, 2014. The pouring date of RFC was from June 8th, 2014, to October 16th, 2014, with the dam height reaching $22 \mathrm{~m}$. Construction work was suspended during the winter period from October 17th, 2014, to April 10th, 2015. Concrete pouring recommenced on April 11th, 2015. The concrete pouring reached the overflow crest on August 10th, 2015, and the dam crest on August 25th, 2015. The reservoir storage began in November 2015 and reached the water depth of $46 \mathrm{~m}$ in June 2016.

4.2.3. Material Parameters. In the overflow section of the dam, the normal concrete C25W6F100 with the second gradation is adopted for cushion, C20W10F150 for upstream and downstream anti-seepage slab, and C40W6F100 for the overflow face. With regard to the main body of the dam, C20W8F150 RFC is employed with a rock-fill ratio of $55 \%$. The thermodynamic parameters of the materials are shown in Table 7.

4.3. Calculation Model. In this section, the finite element calculation model is established for simulating the dam's concrete construction process. The length of the overflow section is $21 \mathrm{~m}$, the bottom width is $37.6 \mathrm{~m}$, and the height is $46 \mathrm{~m}$. As seen in Figure 5, the finite element model takes the left dam heel as its coordinate origin, the direction of water 
TABLE 6: The monthly mean water temperature at the bottom and surface of the reservoir.

\begin{tabular}{|c|c|c|c|c|c|c|c|c|c|c|c|c|}
\hline Month & 1 & 2 & 3 & 4 & 5 & 6 & 7 & 8 & 9 & 10 & 11 & 12 \\
\hline Bottom $\left({ }^{\circ} \mathrm{C}\right)$ & 4.2 & 4.5 & 4.9 & 5.2 & 5.8 & 6.9 & 7.4 & 6.9 & 5.7 & 5.0 & 4.7 & 4.0 \\
\hline Surface $\left({ }^{\circ} \mathrm{C}\right)$ & 2.1 & 2.5 & 4.6 & 6.8 & 8.6 & 12.3 & 16.7 & 14.9 & 11.1 & 9.9 & 1.7 & 1.2 \\
\hline
\end{tabular}

TABLE 7: The thermodynamic parameters of concrete materials for dam.

\begin{tabular}{|c|c|c|c|c|c|}
\hline Material & $\begin{array}{c}\text { Thermal } \\
\text { conductivity } \\
/ \mathrm{kJ} \cdot\left(\mathrm{m} \bullet \mathrm{h} \cdot{ }^{\circ} \mathrm{C}\right)^{-1}\end{array}$ & $\begin{array}{c}\text { Specific } \\
\text { heat } \\
/ \mathrm{kJ} \cdot\left(\mathrm{kg} \bullet{ }^{\circ} \mathrm{C}\right)^{-1}\end{array}$ & $\begin{array}{c}\text { Parameter } \\
\text { Coefficient of } \\
\text { linear } \\
\text { expansion } \\
/ 10^{-6} \bullet^{\circ} \mathrm{C}^{-1}\end{array}$ & $\begin{array}{c}\text { Adiabatic } \\
\text { temperature rise } \\
/^{\circ} \mathrm{C}\end{array}$ & $\begin{array}{l}\text { Elastic } \\
\text { modulus } \\
/ \mathrm{GPa}\end{array}$ \\
\hline $\begin{array}{l}\text { Cushion } \\
\text { concrete }\end{array}$ & 7.000 & 0.9970 & 6.51 & $\theta(\tau)=\frac{34.48 \tau}{\tau+1.39}$ & $E=\frac{32.5 \tau}{\tau+5.5}$ \\
\hline $\begin{array}{l}\text { Anti-seepage } \\
\text { concrete }\end{array}$ & 7.000 & 0.9971 & 6.74 & $\theta(\tau)=\frac{28.5 \tau}{\tau+1.25}$ & $E=\frac{31.8 \tau}{\tau+9.5}$ \\
\hline $\begin{array}{l}\text { Overflow } \\
\text { concrete }\end{array}$ & 7.125 & 1.0021 & 6.96 & $\theta(\tau)=\frac{30.4 \tau}{\tau+1.20}$ & $E=\frac{38.5 \tau}{\tau+5.5}$ \\
\hline $\begin{array}{l}\text { Rock-fill } \\
\text { concrete }\end{array}$ & 7.917 & 1.0018 & 7.18 & $\begin{array}{c}\theta(\tau)= \\
15.45\left(1-\mathrm{e}^{-0.319 \tau^{0.855}}\right)\end{array}$ & $E=\frac{32.0 \tau}{\tau+9.3}$ \\
\hline
\end{tabular}

flow is Y-axis forward, the direction of the vertical flow and pointing to the right bank is $\mathrm{X}$-axis forward, and the dam height is $\mathrm{Z}$-axis forward. Meanwhile the foundation extends twice the height of the dam along its upstream, downstream, and bottom. In addition, the "birth and death" element technology of finite element analysis software ANSYS is used to simulate the rising process of the dam pouring [23]. The calculation step is 1 day in the construction period, and the variable calculation step is $2-30$ days in the operation period. The calculation program of temperature and stress field, developed by ANSYS parametric design language, can help to achieve the automatic calculation of each load step.

The Solid70 element is used in the simulation of the temperature field. The bottom of the foundation, its four sides, and transverse section of the dam are considered as the adiabatic boundary. The upstream and downstream surfaces of the dam are deemed as the third category boundary conditions before reservoir storage. After reservoir storage, the surfaces under the water are considered as the first boundary conditions and above the water are still regarded as the third boundary conditions [24-27]. Solid70 has a 3D thermal conduction capability. The element has eight nodes with a single degree of temperature freedom at each node. The element is applicable to a 3D steady-state or transient thermal analysis [28]. In relation to the simulation of the temperature stress field, Solid185 element is employed, and the bottom of the foundation is a fixed support, with its four sides attaching normal restrictions [24-27]. Solid185 is used for 3D modeling of the solid structures and defined by eight nodes, with three degrees of freedom at each node: translations in the nodal $\mathrm{x}, \mathrm{y}$, and $\mathrm{z}$ directions. The element has plasticity, hyper elasticity, stress stiffening, creep, large deflection, and large strain capabilities [28].

4.4. The Standard of Temperature Control. With regard to the temperature stress control standard of RFC, references should be made to normal concrete. According to the code for "Design of Concrete Gravity Dams" (SL319-2005), the allowable temperature stress of the dam's concrete should be calculated as follows:

$$
\sigma \leq \frac{\varepsilon_{p} E_{c}}{K_{f}}
$$

where $\sigma$ refers to the sum of temperature stress caused by the initial temperature difference, the internal and external temperature difference, and the temperature difference between up-down layers (its unit is $\mathrm{Mpa}$ ); $\varepsilon_{p}$ refers to the ultimate tensile strain of concrete, an important indicator of the cracking resistance of concrete; $E_{c}$ refers to the elastic modulus of concrete (its unit is $\mathrm{GPa}$ ); and $K_{f}$ refers to the safety factor and the value is 1.65 in this project according to its importance and the harmfulness of cracking.

The allowable temperature stress of the dam concrete is presented in Table 8, which was calculated in accordance with the elastic modulus and ultimate tensile strain.

\subsection{The Analysis of Calculation Results}

4.5.1. The Calculation Results Analysis of Temperature Field. Based on the construction schedule of the dam, concrete thermodynamic parameters, external environment temperature, water temperature, and other basic data, the finite element software ANSYS is used to simulate the temperature field of the overflow dam in the whole process. Figure 6 shows the contour map of the quasi-stable temperature field of the dam. Figure 7 shows the envelop map of the maximum temperature of the overflow dam. Figure 8 shows the temperature duration curves of typical points at different heights of RFC in the foundation restraint area; the number represents the height of the dam. The calculation results of the temperature field are as follows. 
TABLE 8: The allowable temperature stress of the dam concrete with different ages.

\begin{tabular}{|c|c|c|c|c|c|c|c|}
\hline \multirow[t]{2}{*}{ Material } & \multirow{2}{*}{$\begin{array}{l}\text { Concrete grade of } \\
\text { strength }\end{array}$} & \multicolumn{2}{|c|}{$\begin{array}{l}\text { Ultimate tensile strain } \\
\qquad\left(\times 10^{-4}\right)\end{array}$} & \multicolumn{2}{|c|}{ Elastic modulus (GPa) } & \multicolumn{2}{|c|}{$\begin{array}{c}\text { Temperature stress } \\
\text { control standard ( } \mathrm{MPa})\end{array}$} \\
\hline & & 90 day & 180 day & 90 day & 180 day & 90 day & 180 day \\
\hline Cushion & C25W6F100 & 1.08 & 1.11 & 30.6 & 31.5 & 1.98 & 2.12 \\
\hline Anti-seepage slab & C20W10F150 & 1.02 & 1.07 & 28.8 & 30.2 & 1.78 & 1.96 \\
\hline Rock-fill concrete & C20W8F150 & 0.78 & 0.85 & 29.0 & 30.4 & 1.37 & 1.56 \\
\hline Overflow face & C40W6F100 & 1.17 & 1.19 & 36.3 & 37.4 & 2.57 & 2.69 \\
\hline
\end{tabular}

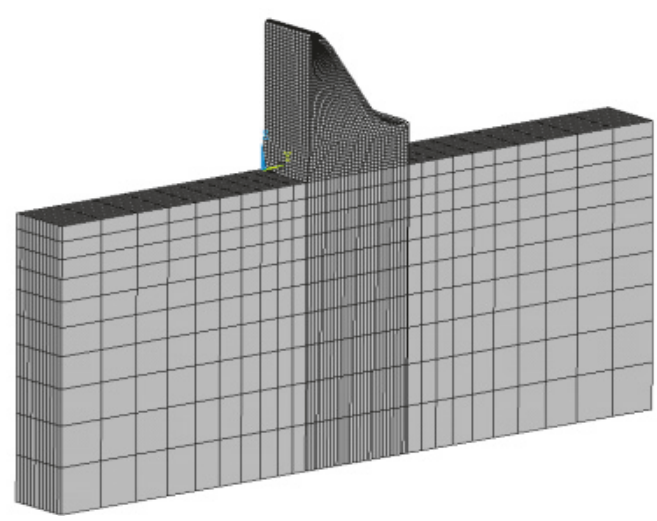

(a) The integral calculation model

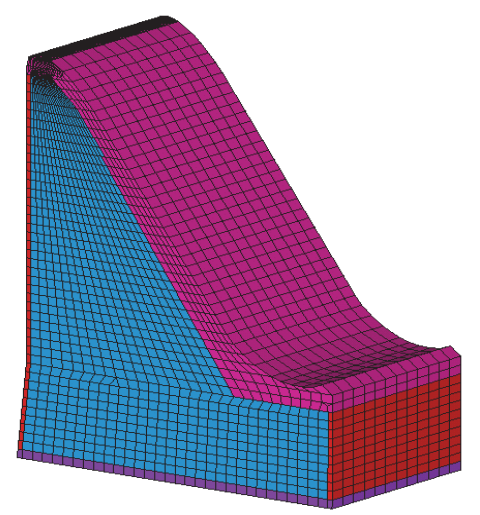

(b) The calculation model of the overflow dam

Figure 5: The finite element model.

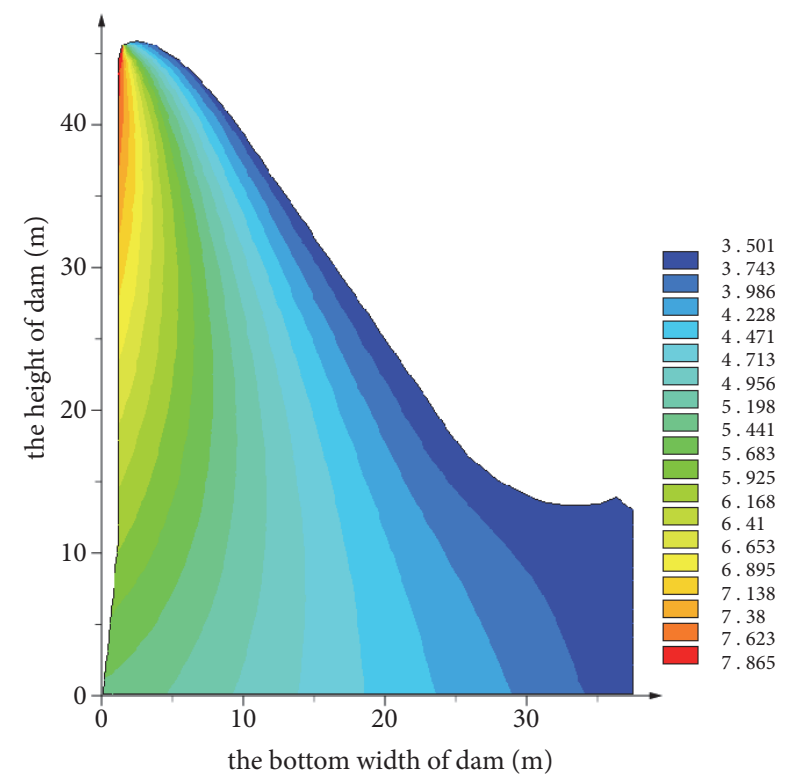

FIGURE 6: The contour map of the quasi-stable temperature field of the dam (unit: ${ }^{\circ} \mathrm{C}$ ).

(1) The maximum temperature of concrete appears inside the dam body and is closely related to the casting season. Owing to the long construction down-time in winter, a longintermission low temperature zone is formed near the dam height of $22 \mathrm{~m}$, and the high temperature area of the dam is

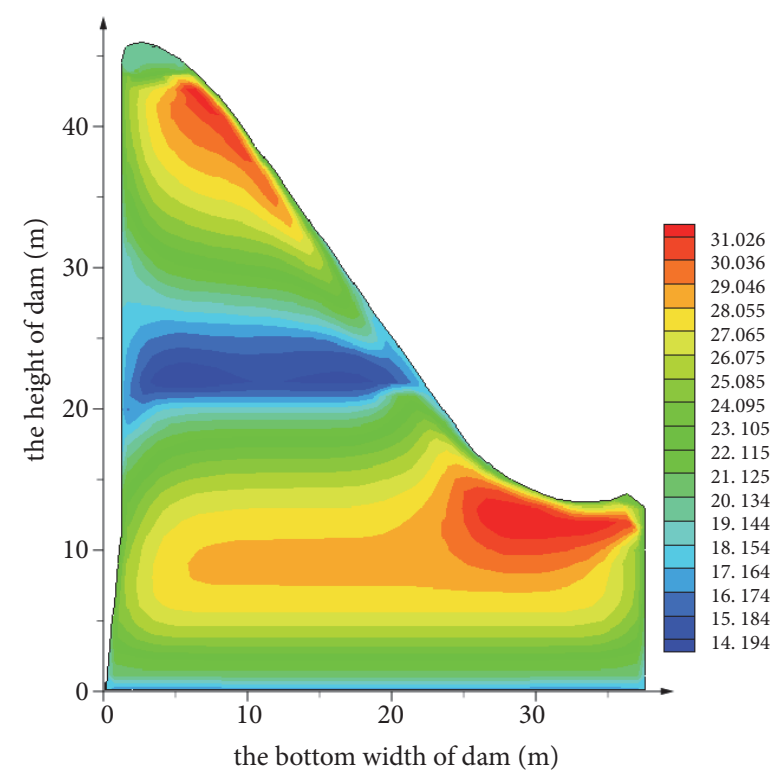

FIGURE 7: The envelop map of the maximum temperature of the overflow dam (unit: ${ }^{\circ} \mathrm{C}$ ).

divided into upper and lower parts. The high temperature areas of the middle to lower and middle to upper parts are poured during high temperature season, from June to September, in which the maximum temperature is $31.0^{\circ} \mathrm{C}$.

(2) The maximum temperature of the RFC in the strong restraint area is $28.5^{\circ} \mathrm{C}$, which appears in the middle part 


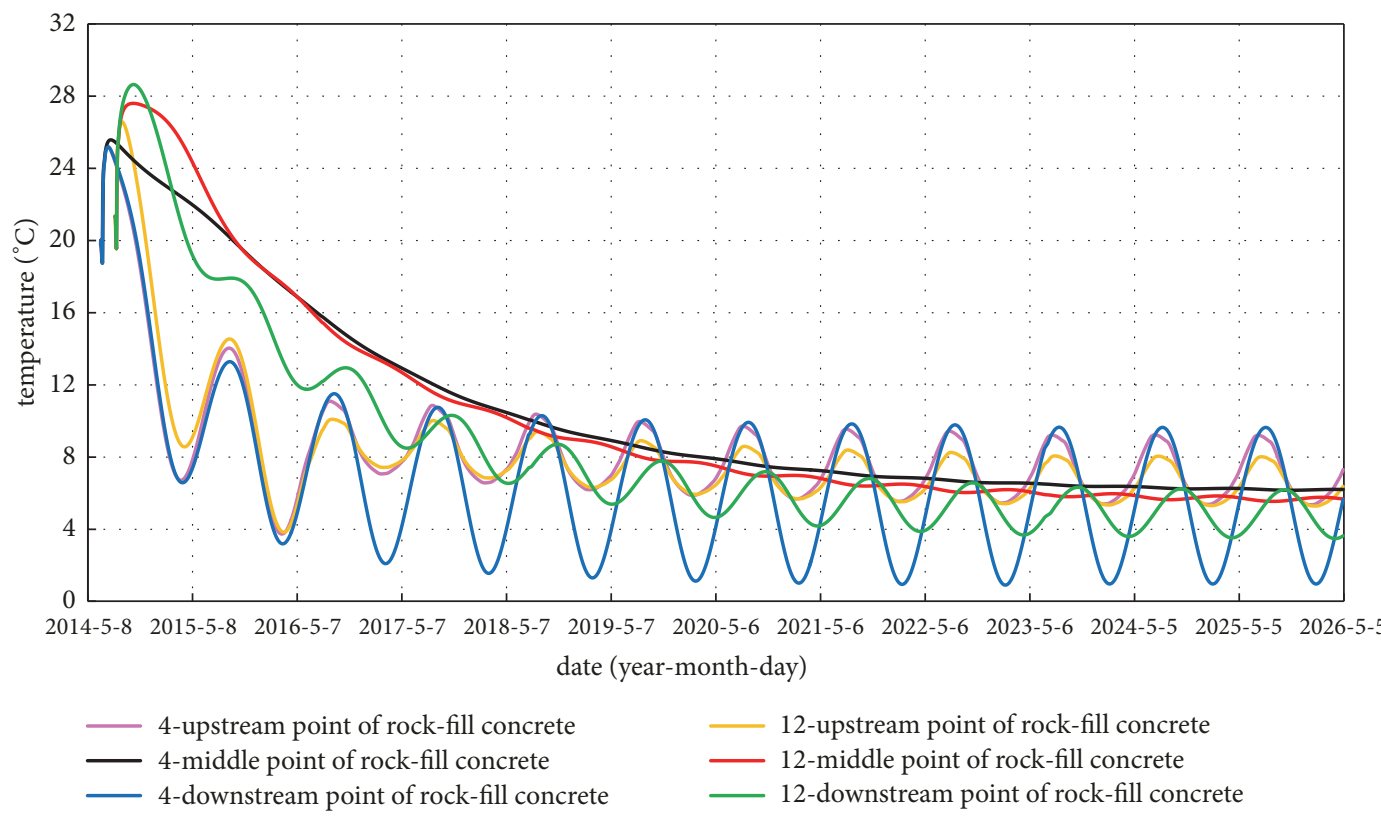

FIGURE 8: The temperature duration curves of typical points at different heights of RFC in the foundation restraint area (the number represents the height of the dam).

of the RFC, while the maximum temperature in the weak restraint area is $31.0^{\circ} \mathrm{C}$, which appears near the overflow face, since the hydration heat of the newly poured normal concrete of the overflow face is transferred to the lower part of the RFC, while the hydration heat of RFC is continuous.

(3) The maximum temperature of the RFC appears in the construction period. As time increases, the maximum temperature gradually decreases. The temperatures of the upstream and downstream typical points at different heights of RFC are greatly influenced by the external environment temperature, which tends to stabilize in the following 3-4 years and varies in a simple harmonic with the ambient temperature. After 10 years of operation, the internal temperature of RFC tends to stabilize at $6^{\circ} \mathrm{C}$.

(4) Before reservoir storage, the upstream and downstream temperature of RFC varies in a simple harmonic with the air temperature. After reservoir storage, the upstream temperature of the RFC varies in a simple harmonic with the water temperature, while the temperature variation is small. While a larger variation of temperature is observed, the downstream temperature of the RFC still varies in a simple harmonic with the air temperature. The calculation results of the dam's temperature field are in accordance with the general law.

4.5.2. The Calculation Results Analysis of Temperature Stress Field. According to the calculated data of the temperature field, the whole-process simulating calculation is performed for the temperature stress of the overflow dam. Figures 9 and 10 show the envelop maps of the first principal stress S1 and the third principal stress S3 of the overflow dam. Figure 11 shows the temperature stress duration curve of typical points

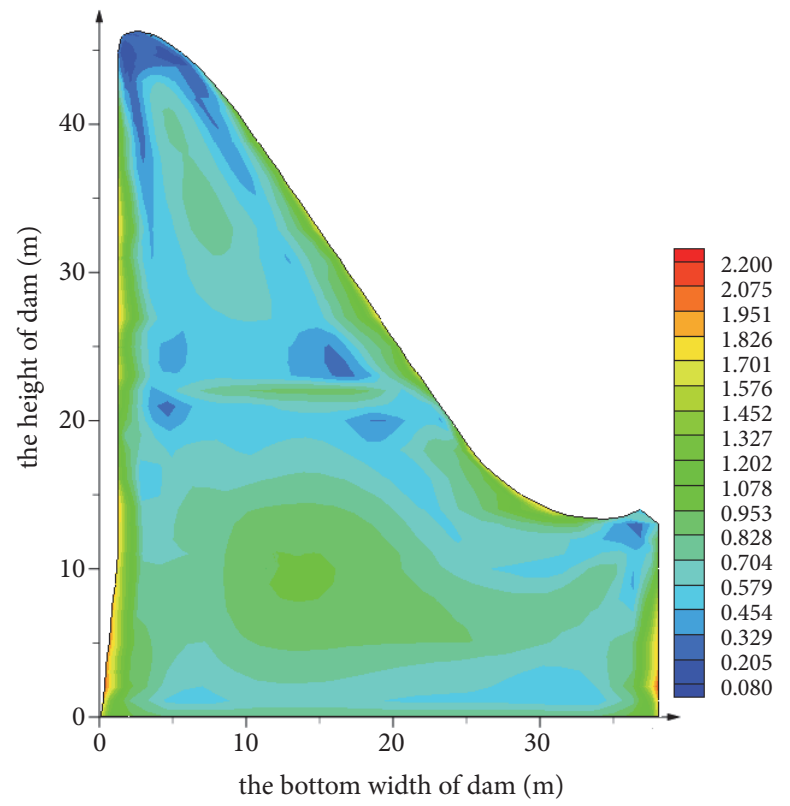

FIGURE 9: The envelop map of the first principal stress $\mathrm{S} 1$ of the overflow dam (unit: $\mathrm{MPa}$ ).

on the long-intermission surface. The maximum temperature stress and occurrence age of different parts of the overflow dam are shown in Table 9. The calculation results of the temperature stress are as follows.

(1) The maximum temperature stresses of the cushion concrete, upstream and downstream anti-seepage concrete, and overflow concrete are $1.87,1.93$, and $1.74 \mathrm{MPa}$, respectively, which all appear on the surface of the dam in low 
TABLE 9: The maximum temperature stress and occurrence age of different parts of the overflow dam.

\begin{tabular}{lcccc}
\hline & Cushion concrete & Rock-fill concrete & $\begin{array}{c}\text { Upstream and downstream } \\
\text { anti-seepage concrete }\end{array}$ & Overflow concrete \\
\hline $\begin{array}{l}\text { Temperature Stress (MPa) } \\
\text { Occurrence age (Day) }\end{array}$ & 1.87 & 0.93 & 1.93 & 1.74 \\
Location & 250 & 2993 & $\begin{array}{c}241 \\
227\end{array}$ & $\begin{array}{c}\text { Anti-arc section of } \\
\text { overflow surface }\end{array}$ \\
\hline
\end{tabular}

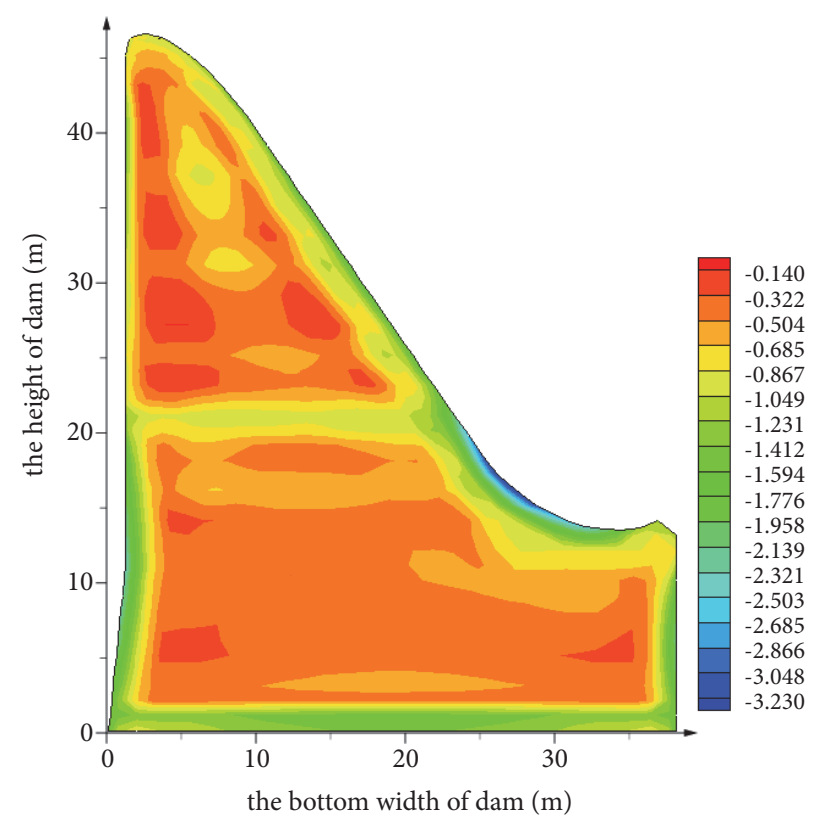

FIgURE 10: The envelop map of the third principal stress S3 of the overflow dam (unit: MPa).

temperature seasons. The main reason is that the middle to lower part of the dam's concrete is poured in high temperature season, generating higher hydration heat temperature and casting temperature, which leads to higher concrete temperature. In winter, the larger temperature difference between the inside and outside of the dam results in a greater temperature stress. Moreover, the maximum temperature stress of the RFC is $0.93 \mathrm{MPa}$, which appears inside the dam in high temperature seasons. The maximum temperature stress of each part of the dam is less than the allowable tensile strength at the age of 180 days.

(2) The maximum temperature stress inside the RFC on the long intermission surface (at the height of $22 \mathrm{~m}$ ) is $0.92 \mathrm{MPa}$, which appeared on January 2nd, 2014 (at the age of 240 days). As for the upstream and downstream anti-seepage concrete, the maximum temperature stress is $1.41 \mathrm{MPa}$, which appeared on January 2nd, 2015 (at the age of 605 days). Besides, the maximum temperature stress of the overflow concrete is 1.21 MPa, which appeared on January 4th, 2015 (at the age of 607 days). The maximum temperature stresses are all less than the allowable tensile strength at the age of 180 days.

(3) During the low temperature season (from November to April), the surface stress of the dam is mainly characterized by the tensile stress, while the surface stress manifests itself in the compressive stress in high temperature season (from May to October). The surface stress of the dam varies in a simple harmonic with the air temperature and water temperature. The calculation results of dam's temperature stress field conform to the general law.

\section{Conclusion}

(1) The adiabatic temperature rise of RFC with a rock-fill ratio of $42 \%, 49 \%$, and $55 \%$ is $19.11^{\circ} \mathrm{C}, 17.32^{\circ} \mathrm{C}$, and $15.45^{\circ} \mathrm{C}$, respectively, which is negatively correlated with the rock-fill ratio. Moreover, the temperature rise rate of the hydration heat of RFC decreases with an increase in the rock-fill ratio and concrete age.

(2) The adiabatic temperature rise test results coincide with the theoretical calculations quite well, and the deviation is less than $0.5^{\circ} \mathrm{C}$. Therefore, the calculation model of the adiabatic temperature rise of RFC, proposed in the present study, is characterized with high accuracy, which can provide the theoretical basis for predicting the adiabatic temperature rise of RFC with different rock-fill ratios.

(3) Without any temperature control measures, the maximum temperature stress of RFC generated by the temperature rise of hydration heat in the RFC gravity dam is $0.93 \mathrm{MPa}$, which meets the stress control standard and further ensures 


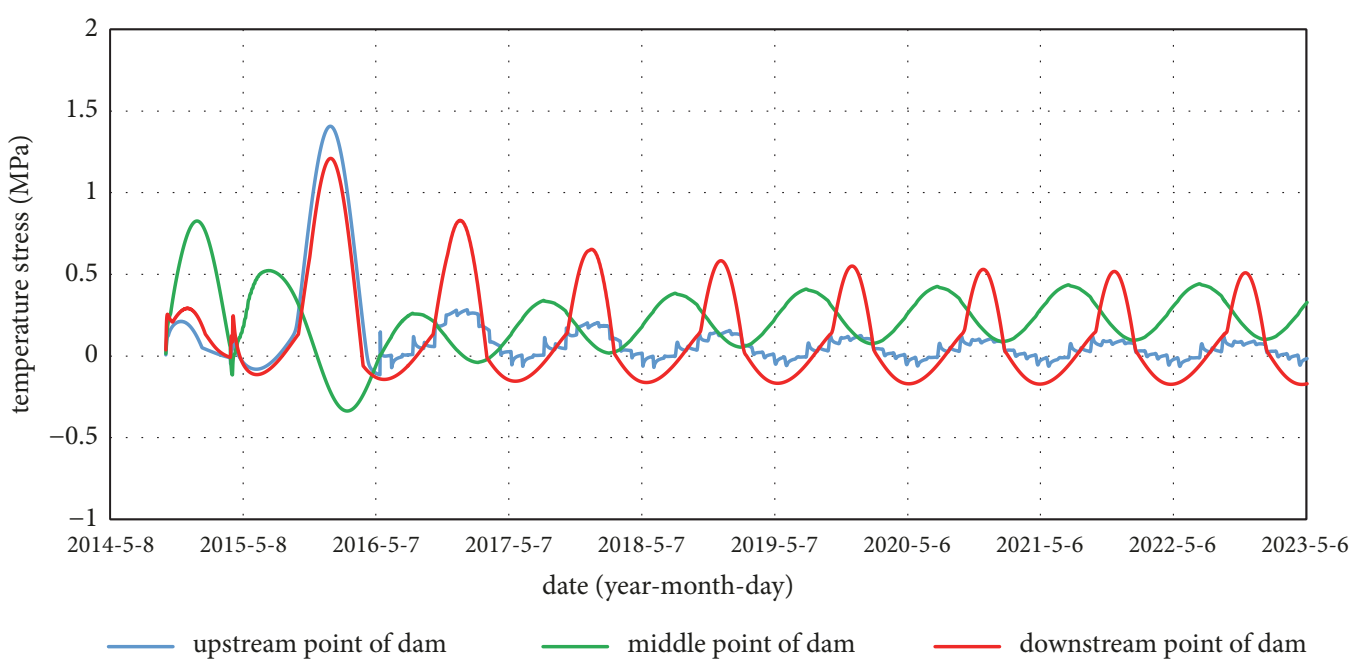

FIGURE 11: The temperature stress duration curves of the typical points on the long-intermission surface (at the height of $22 \mathrm{~m}$ )

the safety of the dam under the temperature load. On this basis, it can be concluded that RFC, compared with common concrete of corresponding strength grade, can simplify the measure of temperature control and cracking prevention, improve construction efficiency, and reduce the cost of the dam construction.

\section{Data Availability}

The data used to support the findings of this study are included within the article.

\section{Conflicts of Interest}

The authors declare that there are no conflicts of interests regarding the publication of this paper.

\section{Acknowledgments}

This research is financially supported by the National Nature Science Foundation of China (No. 51479168).

\section{References}

[1] B. Persson, "A comparison between mechanical properties of self-compacting concrete and the corresponding properties of normal concrete," Cement and Concrete Research, vol. 31, no. 2, pp. 193-198, 2001.

[2] H. J. H. Brouwers and H. J. Radix, "Self-compacting concrete: Theoretical and experimental study," Cement and Concrete Research, vol. 35, no. 11, pp. 2116-2136, 2005.

[3] C. Zhang, F. Jin, S. Chen, and X. Xu, "Flow behaviors of selfcompacting concrete in rockfill gaps," Journal of Hydroelectric Engineering, vol. 35, no. 10, pp. 112-120, 2016 (Chinese).

[4] Y. Xie, D. J. Corr, M. Chaouche, F. Jin, and S. P. Shah, "Experimental study of filling capacity of self-compacting concrete and its influence on the properties of rock-filled concrete," Cement and Concrete Research, vol. 56, pp. 121-128, 2014.
[5] S. He, C. Chen, H. Zhou, and F. Jin, "Current research on comprehensive properties of rock filled concrete," Journal of Hydroelectric Engineering, vol. 36, no. 5, pp. 10-18, 2017 (Chinese).

[6] F. Jin, X. H. An, J. J. Shi et al., "Study on rock-fill concrete dam," Journal of Hydraulic Engineering, vol. 36, no. 11, pp. 1347-1352, 2005 (Chinese).

[7] J. Jia, M. Lino, F. Jin, and C. Zheng, "The cemented material dam: a new, environmentally friendly type of dam," Engineering, vol. 2, no. 4, pp. 490-497, 2016.

[8] X. H. An, Q. Wu, and F. Jin, "Rock-filled concrete, the new norm of SCC in hydraulic engineering in China," Cement and Concrete Composites, vol. 54, no. 54, pp. 89-99, 2014.

[9] M. Huang, X. H. An, and H. Zhou, "Rock-Filled ConcreteDevelopment, investigation and applications," International Water Power and Dam Construction, vol. 60, pp. 20-24, 2008.

[10] M. Kaszynska, "Early age properties of high-strength/highperformance concrete," Cement and Concrete Composites, vol. 24, no. 2, pp. 253-261, 2002.

[11] B. F. Zhu, Temperature Stress and Temperature Control of Mass Concrete, China Water Conservancy and Hydropower Press, Beijing, 2nd edition, 2012, (Chinese).

[12] B. F. Zhu, "Current situation and prospect of temperature control and cracking prevention technology for concrete dam," Journal of Hydroelectric Engineering, vol. 5, no. 4, pp. 415-428, 2006 (Chinese).

[13] B. F. Zhu, "Method for computing the adiabatic temperature rise of concrete considering the effect of the temperature of concrete," Journal of Hydroelectric Engineering, no. 2, pp. 69-73, 2003 (Chinese).

[14] C.-K. Lim, J.-K. Kim, and T.-S. Seo, "Prediction of concrete adiabatic temperature rise characteristic by semi-adiabatic temperature rise test and FEM analysis," Construction and Building Materials, vol. 125, pp. 679-689, 2016.

[15] F. Tomosawa, "Development of a kinetic model for hydration of portland cement," in Proceedings of the Tenth International Congress of the Hydration of Portland Cement, Goteburg, Sweden, 1997.

[16] H. M. Jennings, J. J. Thomas, J. S. Gevrenov, G. Constantinides, and F.-J. Ulm, "A multi-technique investigation of the 
nanoporosity of cement paste," Cement and Concrete Research, vol. 37, no. 3, pp. 329-336, 2007.

[17] W. Yao and W. Wang, "Numerical simulation of adiabatic temperature rise of concrete," Journal of Hydraulic Engineering, vol. 45, no. 5, pp. 626-630, 2014 (Chinese).

[18] I. Y. T. Ng, P. L. Ng, and A. K. H. Kwan, "Effects of cement and water contents on adiabatic temperature rise of concrete," ACI Materials Journal, vol. 106, no. 1, 2009.

[19] P. L. Ng, I. Y. T. Ng, and A. K. H. Kwan, "Adiabatic temperature rise of incompletely hydrated cement concrete," Key Engineering Materials, vol. 400-402, pp. 157-162, 2009.

[20] L. C. Wang, D. Wu, J. W. Bao et al., "Mesoscale numerical simulation analysis for temperature distribution in early-age concrete," Journal of Hydraulic Engineering, vol. 48, no. 9, pp. 1015-1022, 2017.

[21] G. Mai, X. W. Tang, and Z. P. Tang, "An analytical method for temperature field distribution of rock-fill concrete structure," Journal of Yangtze River Scientific Research Institute, no. 12, pp. 97-100, 2013 (Chinese).

[22] A. G. Evsukoff, E. M. R. Fairbairn, É. F. Faria, M. M. Silvoso, and R. D. T. Filho, "Modeling adiabatic temperature rise during concrete hydration: a data mining approach," Computers and Structures, vol. 84, no. 31-32, pp. 2351-2362, 2006.

[23] Y. Chen, C. Wang, S. Li, R. Wang, and J. He, "Simulation analysis of thermal stress of RCC dams using 3-D finite element relocating mesh method," Advances in Engineering Software, vol. 32, no. 9, pp. 677-682, 2001.

[24] A. I. H. Malkawi, S. A. Mutasher, and T. J. Qiu, "Thermalstructural modeling and temperature control of roller compacted concrete gravity dam," Journal of Performance of Constructed Facilities, vol. 17, no. 4, pp. 177-187, 2003.

[25] P. Léger, J. Venturelli, and S. S. Bhattacharjee, "Seasonal temperature and stress distributions in concrete gravity dams. Part 1: modelling," Canadian Journal of Civil Engineering, vol. 20, no. 6, pp. 999-1017, 1993.

[26] J. Noorzaei, K. H. Bayagoob, W. A. Thanoon, and M. S. Jaafar, "Thermal and stress analysis of Kinta RCC dam," Engineering Structures, vol. 28, no. 13, pp. 1795-1802, 2006.

[27] J. Zhang, C. Huang, C. Lu, L. Han, P. Wang, and G. Li, "Automatic thermal analysis of gravity dams with fast boundary face method," Engineering Analysis with Boundary Elements, vol. 41, pp. 111-121, 2014.

[28] B. Zhang and H. T. Sheng, ANSYS Finite Element Numerical Analysis Principle and Engineering Application, Tsinghua University Press, 2005, (Chinese). 


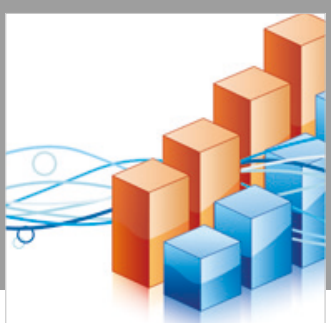

Advances in

Operations Research

\section{-n-m}
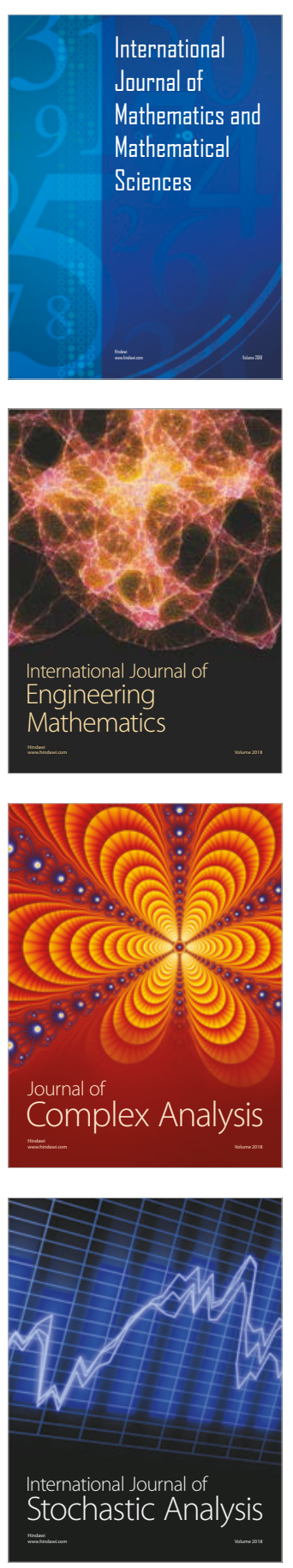
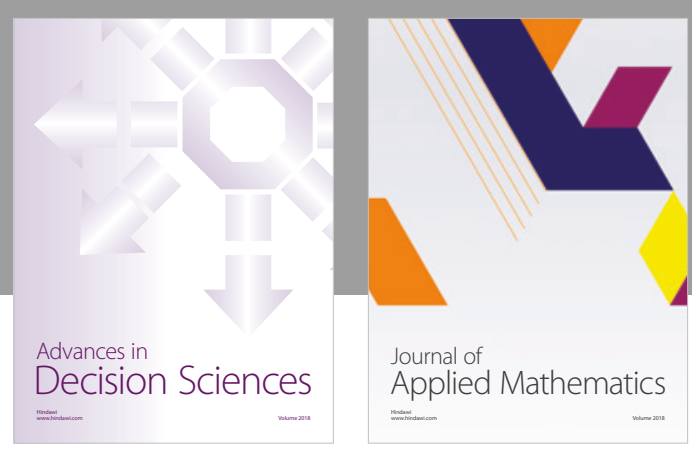

Journal of

Applied Mathematics
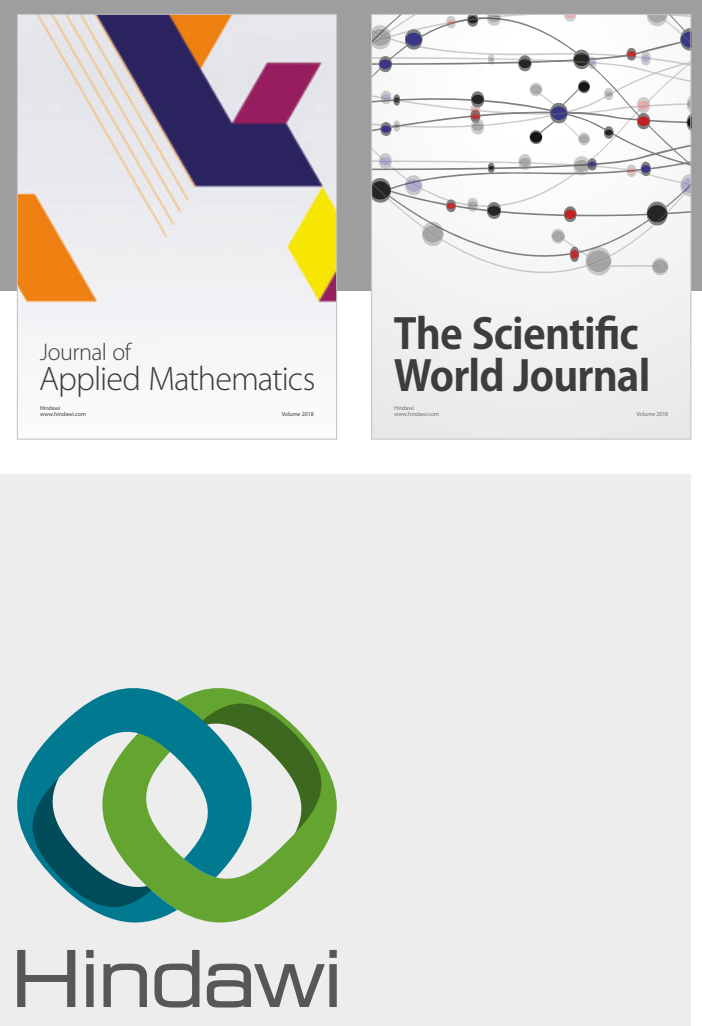

Submit your manuscripts at

www.hindawi.com

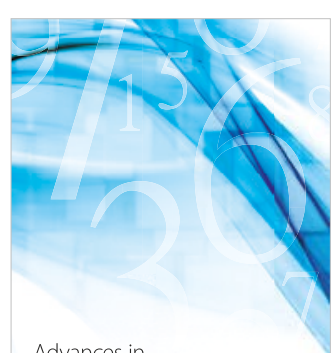

Advances in
Numerical Analysis
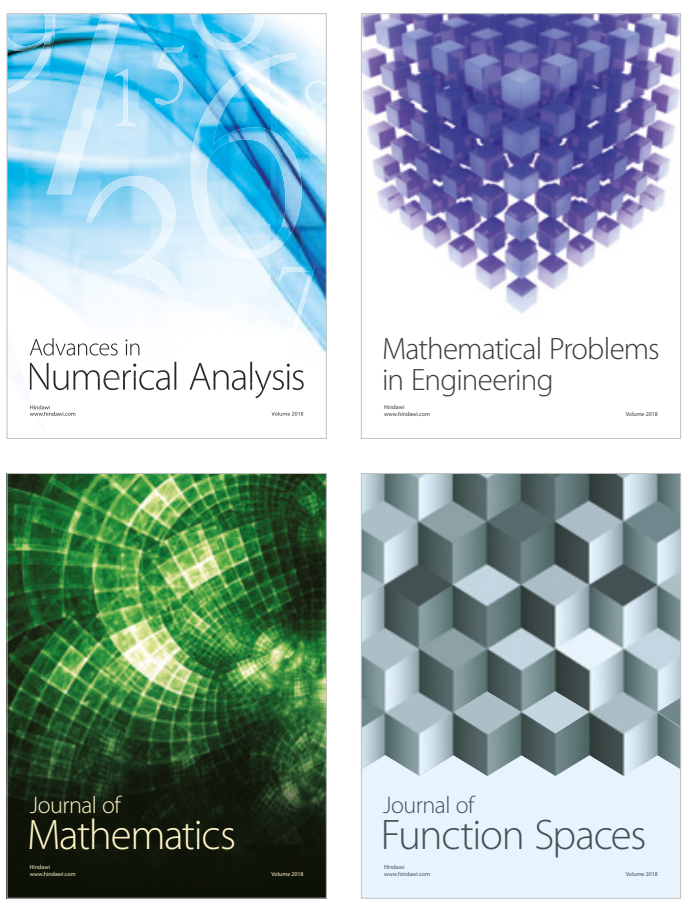

Mathematical Problems in Engineering

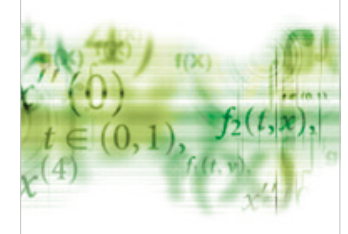

International Journal of

Differential Equations

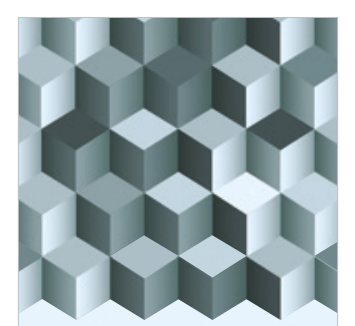

Journal of

Function Spaces
The Scientific

World Journal

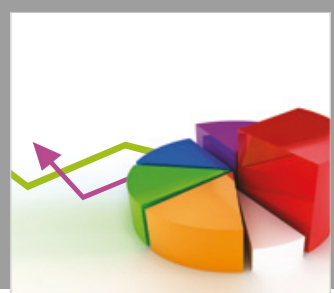

Journal of

Probability and Statistics
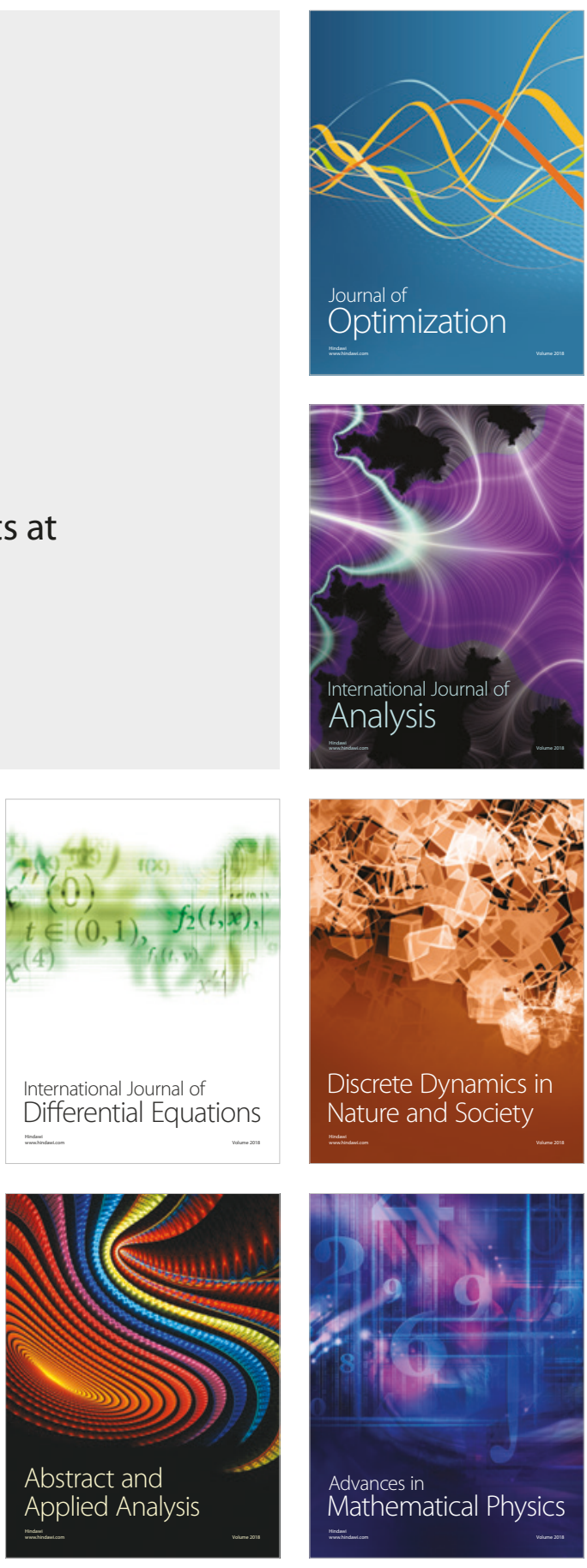